\title{
A Correlational Study to Assess The Relationship of Internet Use With Depression Among Adolescents In Selected Schools of Amritsar, Punjab
}

\author{
Navdeep Kaur ${ }^{1}$ Amanpreet Kaur ${ }^{2}$ Monika Dogra ${ }^{3}$ \\ 1.Lecturer, CON AIMS, Shri Muktsar Sahib \\ 2.Reader, Khalsa College of Nursing, Amritsar \\ 2.Lecturer, Khalsa College of Nursing, Amritsar \\ Corresponding E-mail: jatananavdeep@gmail.com
}

\begin{abstract}
Introduction: Adolescence is the transient period from childhood to maturity. In this period, adolescents are curious to know about environment, public figures and forming new relationships. For this, many use internet various many reasons but its excessive use among adolescents make them lonely, unhappy and depressed.

Aim of the study: To assess the relationship of internet use with depression among the adolescents in order to create awareness among adolescents regarding its harmful impact on their health and life.

Material and Methods: The present study explored the 8 schools of Amritsar, Punjab. The sample consisted of 300 adolescents studying in selected schools. Purposive sampling technique was followed to select the sample. Internet use was assessed by questionnaire on internet usage and depression was measured by Beck Depression Inventory (BDI).

Results: The study findings revealed that nearly half (50.7\%) of the adolescents were normal i.e. having no depressive symptoms. Out of 300, $121(40.3 \%)$ had mild mood disturbance whereas $27(9.0 \%)$ of them were found suffering with borderline clinical disturbance. Pearson's coefficient of correlation showed negative $(\mathrm{r}=-0.029)$ correlation between Internet use and depression. Chi-square was applied to assess the relationship of internet use and depression among adolescents with socio-demographic variables such as age, gender, class, residence, type of family, family income, mode of internet access, frequency of internet use and duration of time spent on internet. None of the socio-demographic variables showed relationship of internet with depression among adolescents. Only one variable i.e. class in which adolescents were studying this relationship was found significant.

Conclusion: This study revealed that majority of the adolescents were mild internet users, majority of them were normal with no depression, about $121(40.3 \%)$ of the adolescents had mild mood disturbances. Also, it is revealed that as the internet use was increasing, the depression went down and vice versa.

Key words: Internet Use, Depression, Adolescents
\end{abstract}

\section{INTRODUCTION\& BACKGROUND OF THE STUDY :}

Adolescence is a stepping stone from childhood to maturity. So life-style, that adolescents are exposed to, determine the rest of their lives. Habits formed in this crucial period like driving a vehicle, voting, entering into contacts, purchasing, searching for new things and focus on romantic partner. These may last to the end and demand special care and attention of parents and society.

Modern technological advancement has offered man a lot, all of which aims primarily at making human lives better. Internet is the superb communication system that has done a lot of miracles beyond belief. A flood of information could be linked into at the flick of computer switch. In this internet world human beings have their brain left free as they don't have to memorize things. This communication system is making humans dull and less dependent on their own sharp senses.

Pritt Kallas (2009)2 mentioned that the internet is being widely used around the world and has found its way into $80 \%$ of household in most developed countries. Popular networking sites such as facebook recorded an immense 350 million users in 2010. Among all the internet users $73 \%$ have profile on facebook, $48 \%$ have a profile on MySpace and about $8 \%$ aged between 12-17 years use twitter which is another social site for visiting a world of virtual reality. 
Adolescents are mostly curious to make online relationship. They communicate about their lives and update their activities for their friends on social networking sites. Facebook is currently the most commonly used online social networking among children. The personal information displayed on the profile page is exaggerated to look impressive. Girls mostly put their good looking profile pictures and boys put personal information, political views, status as a single and mobile numbers openly to impress the viewers.

As internet increasingly becomes a part of our lives, some users may develop emotional attachments to on-line friends and activities that allow them to escape from reality and fulfil unmet emotional and psychological needs without having to deal with real life relationships. When a girl and a boy make a relationship on internet and if it breaks they become anxious and might lead to depression. The children do emails and text massages to each other and keep on waiting for reply and if in case they do not get reply they become sad, restless and depressed. They spend several hours on internet, start skipping their work, miss schools, start giving poor performance at school and keep awake at night, ultimately it starts interfering with their daily activities.

The time spent and the level of internet use, goes on ever increasing that it crosses the healthy limit. Emotionally hungry, they look up for friends through social networking sites, where they make fake accounts with fake profiles. Feeling socially and emotionally insecure children stoop to the overuse of profiles. They interact not only with their known friends and classmates but also with the unknown strangers where they share private feelings without any hesitation. Eagerly they wait for the responses from their virtual friends and this curiosity start putting pressure on them.Sometime they start sending unwanted emails. These unwanted emails obstruct the entire system. Such illegal activities even cause frustration. Posture and visual cost of their excessive use of internet is extra burden to their emotional and social health.

\section{AIM OF THE STUDY}

The aim of the study was to assess the relationship of internet use with depression among the adolescents in order to create awareness among adolescents regarding its harmful impact on their health and life.

\section{MATERIALAND METHODS}

To accomplish the objectives of study, a non experimental research approach was employed to assess the relationship of Internet Use with Depression among adolescents. A correlational design was chosen for the present study. The study was conducted in various schools of Amritsar, Punjab. The target population of the study consisted of all the adolescents studying in selected schools of Amritsar, Punjab. Purposive sampling technique was adopted to collect data. Total 300 adolescents were selected as study subjects who were meeting the inclusion and exclusion criteria. A five point likert internet usage scale and modified beck depression inventory scale was used. Tool of the study consisting of

Part 1- Socio demographic data 9 items

Part 2- A five point likert scale was prepared to assess the internet use among adolescents. It includes total 20 items regarding internet use.

Part 3- Modified Beck Depression Inventory scale 20 multiple-choice items regarding assessment of level of depression.

Content validity of the tool was established by giving the questionnaire to 10 experts in the field of nursing and medical sciences. Reliability of likert scale and modified scale was computed by applying split half method and by Karl Pearson's coefficient co-relation and Spearman Brown prophecy formula and reliability of likert scale was 0.62 and for modified scale was found 0.71 hence the both tools were reliable.

The data was carried on during the school hours from January 7, 2013 to February 4, 2013. Data analysis was done as per the objectives of the study. The data has been analyzed using Descriptive (Percentages, Frequencies, Standard deviation) and Inferential statistics (Pearson chi-square). The level of $<0.05$ for significance was selected for the study. Data has been presented in the form of tables, bar and pie diagrams.

\section{Ethical Consideration}

This study has been approved by the ethical committee of Khalsa College of Nursing, Amritsar, Punjab. Verbal consent was taken from the parents and also from the adolescents after informing about study. Confidentiality of information was maintained through the data collection.

\section{RESULTS:}

The analysis of data is presented according with the objectives of st $u$ dy. 
Objective 1: To assess the level of internet use among adolescents

Table 1: Frequency and percentage distribution of adolescents according to level of internet use

\begin{tabular}{|l|c|c|}
\hline Level of internet use & N & \% \\
\hline Mild Internet users & 139 & 46.3 \\
\hline Moderate Internet users & 132 & 44.0 \\
\hline Severe Internet users & 21 & 7.0 \\
\hline Addicted & 8 & 2.7 \\
\hline
\end{tabular}

Maximum score $=100$ Minimum Score $=20$

Table 1 and figure 1 depict the frequency and percentage distribution of level of internet use among adolescents. It shows that most of them $(46.3 \%)$ were mild internet users followed by moderate internet users (44.0\%), whereas very few $(7 \%)$ were found in severe internet users and addicted category $(2.7 \%)$ Hence it is concluded that majority of school going adolescents were mild and moderate internet users.

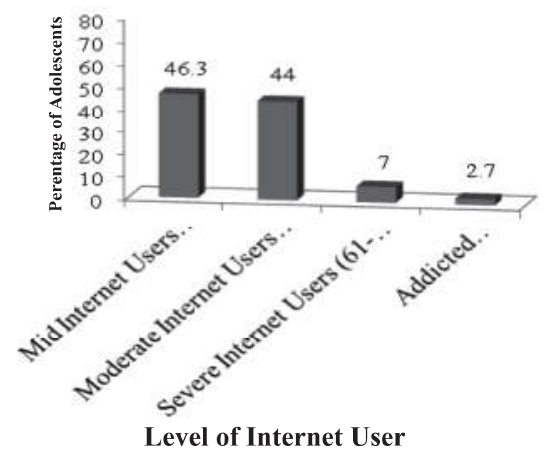

Figure 1 : Percentage distribution of level of internet use among adolescents

Objective 2: To assess the level of depression among adolescents.

Table 2: Frequency and percentage distribution of adolescents according to level of depression

\begin{tabular}{|l|c|c|}
\hline Level of Depression & N & \% \\
\hline Normal & 152 & 50.7 \\
\hline Mild Mood Disturbance & 121 & 40.3 \\
\hline Borderline clinical Disturbance & 27 & 9.0 \\
\hline Moderate Depression & 0 & 0 \\
\hline Severe Depression & 0 & 0 \\
\hline
\end{tabular}

Maximum Score $=60 \quad$ Minimum Score $=0$

Table 2 and figure 2 shows frequency and percentage distribution of adolescents. It shows that nearly half of adolescents $(50.7 \%)$ were normal with no depression followed by those $(40.3 \%)$ with mild mood disturbance and remaining $(9 \%)$ were found with borderline clinical disturbance. None of them was found in moderate and severe depression category. Hence it is concluded that maximum of the school going adolescents were suffering with mild to moderate mood disturbance.

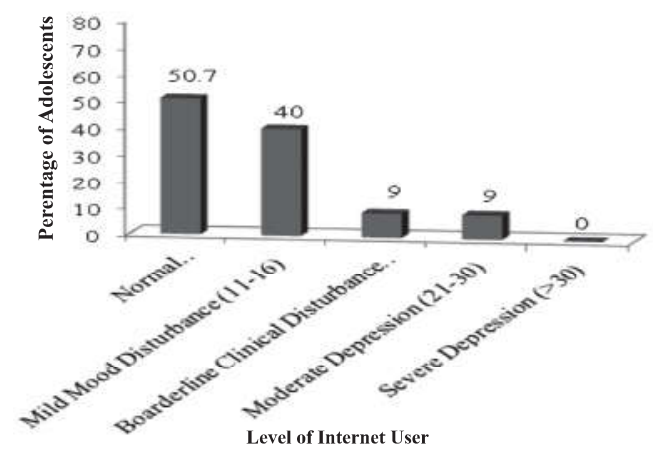

Figure : 2 Percentage of level of depression among adolescents

Objective 3 : To correlate the internet use and depression among adolescents

Table 3: Correlation of internet use and depression among adolescents

$\mathrm{N}=300$

\begin{tabular}{|l|c|c|l|}
\hline Variable & Mean & SD & Coefficient of Correlation(r) \\
\hline Internet Use & 43.38 & 5.11 & \\
Depression & 9.6 & 5.13 & $-0.029^{\mathrm{NS}}$ \\
\hline
\end{tabular}

* Internet user score : Maximum score $=100$ Minimum score $=20$

* Depression Score : Maximum score $=60$ Minimum score $=0$

Table 3 represents the correlation of the internet use and depression among adolescents. It shows that mean \pm SD for internet use was $43.38 \pm 5.11$ and mean \pm SD of depression was $9.6 \pm 5.13$. The coefficient of correlation of internet use and depression among adolescents was calculated and was found to be negatively correlated $(\mathrm{r}=-0.029)$ at $\mathrm{p}<0.05$. Hence it can be concluded that as internet use was increasing, the depression went down and vice versa.

\section{Findings related to relationship of internet use with} depression with selected variables

Results related to the relationship of internet use among adolescents with selected socio-demographic variables such as age, gender, class, residence, type of family, family income, mode of internet access, frequency of internet use and duration of time spent on internet revealed that there was statistically significant 
relationship between class and internet use $(\alpha 2=0.00$ at $\mathrm{p}<0.05$ ). However, no significant relationship was found between depression and any of other sociodemographic variables.

\section{CONCLUSION}

It can be concluded that majority of adolescents were mild internet users $(46.3 \%)$, followed by those who were moderate internet users (44\%), severe internet users (7\%) and were addicted $(2.7 \%)$ to internet use. About half $(50.7 \%)$ of adolescents were normal with no depression, $40.3 \%$ had mild mood disturbance, $9 \%$ of had borderline clinical disturbance, no one was found in moderate and severe depression category. A negative correlation was found between internet use and depression. The relationship of internet use and depression was found with socio-demographic variables such as age, gender, class, residence, type of family, family income, mode of internet access, frequency of internet use and duration of time spent on internet, no one was found statistically significant at $p<0.05$. Only the class was found significant in relation with internet use.

\section{IMPLICATIONS:}

The study finding have certain important implications for the nursing profession i.e. in clinical practice, nursing education, nursing administration and nursing research.

\section{Nursing education}

Nursing students and nursing educators can plan teaching programs including parents and teachers. They can teach about healthy use of internet for the prevention of the symptoms of depression. School Health Nurse should provide guidance and counselling services to adolescents which will help them to lead healthy life.

\section{Nursing Research}

The researcher found adolescents have limited knowledge regarding how to use internet in healthy way. Through the publications of research findings, the knowledge of nurses and adolescents can be improved regarding the use of internet in healthy way and reduce the mood disturbance due to internet use.

\section{Nursing Practice}

The findings of the present study has significance in practice of school health nurses, where they can utilise the findings to suggest and counsel adolescents and their parents regarding internet use and its possible outcome.

\section{Nursing administration}

Nurse administrator can conduct the information, education and communication for staff nurses and nursing students to improve the attitude regarding internet use and identification of mood disturbance

\section{RECOMMENDATIONS}

On the basis of finding of study it is recommended that

$>$ Similar study can be replicated on a large sample for making a more valid generalization.

$>$ Further studies can be conducted on relationship of internet use with anxiety and lonliness.

$>$ A structured teaching programme can be planned and evaluated regarding teachers and adolescents knowledge on internet use and depression.

\section{REFERENCES :}

1. Wonder Stevie. We all have ability, the difference is how we use it, http: //iwise.com/reviwed on 13/03/2013.

2. Kallas Priit. Internet and social media use among millennial generation,

http://www.draeamgrow.com/reviewed on 23/1/ 2012.

3. Nielsen. A report on myths and realities of teen media trends, http://www.nielsen.com/reviewed on $23 / 1 / 2012$.

4. Rotunda, Kass SJ, Sutton MA, Leon DT. Internet use and misuse Journal of Psychology Sept 2003; $27(4): 484-504$.

5. Pantic I, Damjanovic A, Todorovic J, Topalovic D, Bojovic-Jovic D, Ristic S, association between online social networking and depression in high school students Journal of Psychiatric Mar 2012; 24 (1) 90-93.

6. Bessiere K, Pressman S, Kiesler S, Kraut R. Effects of internet use on health and depression : a longitudinal study Journal of Research Feb 2010; 12(1): 96.

7. Ryu EJ, Choi KS, Seo JS, Nam BW. The relationships of Internet addiction, depression, and suicidal ideation in adolescents. Journal of child Psychiatry 2004 Feb; 34 (1): 102-110.

8. Poli R, Agrimi E. Internet addiction disorder among italian students. Journal of Psychiatry. Feb 2012; 66(1): 55-59.

9. Haung C. Internet use and psychological well being. Journal of psychology 2010 Jun;13(3): 241-249.

10. Wang LS. An investigation on prevalence of internet addiction disorder in middle school students. Journal of psychiatric. May 2007; 28(5): 445-448. 